\title{
Unexpected formation of 9,10-dibenzoylphenanthrene
}

\author{
Alan P. Marchand, ${ }^{* a}$ Gadthula Srinivas, ${ }^{a}$ and William H. Watson, $* b$ \\ a Department of Chemistry, University of North Texas, Denton, Texas 76203-5070 USA \\ ${ }^{b}$ Department of Chemistry, Texas Christian University, Fort Worth, Texas 76129-8860 USA \\ E-mail: marchand@unt.edu (organic synthesis, compound characterization) \\ w.watson@tcu.edu (X-ray crystallography)
}

\section{Dedicated to Professor Sukh Dev on the occasion of his $80^{\text {th }}$ anniversary. SATAMANAM BHAVATI SATAYU}

(received 09 Oct 02; accepted 04 Nov 02; published on the web 21 Nov 02)

\begin{abstract}
When heated in the presence of atmospheric oxygen, either in diffuse room light or in the dark, phencyclone (1) undergoes autoxidation to afford 9,10-dibenzoylphenanthrene (3). The structure of 3 was elucidated via application of single crystal X-ray crystallographic techniques. A mechanism is suggested to account for the formation of $\mathbf{3}$ via (i) stepwise 1,4-addition of ${ }^{3} \mathrm{O}_{2}$ to the 1,3-diene system in the cyclopentadiene moiety of $\mathbf{1}$ to form endoperoxide $\mathbf{5}$ followed by (ii) cheletropic extrusion of carbon monoxide from $\mathbf{5}$. The structure of $\mathbf{3}$ is described: $\mathrm{P} 21 / \mathrm{C}, \mathrm{a}=$ 12.116(2), $b=9.6850(2), c=16.839(3) \AA, \beta=100.331(3)^{\circ}$.
\end{abstract}

Keywords: Phencyclone, oxidative degradation, Diels-Alder reaction, X-ray crystal structure

\section{Introduction}

As part of a continuing program that involves the study of cage-annulated crown ethers, ${ }^{1}$ it was of interest to introduce a fluorescent moiety into the macrocyclic polyether backbone. As a first step toward the preparation of a fluorescent ligand, we attempted to perform Diels-Alder cycloaddition of 2-butyne-1,4-diol to 1,3-diphenyl-2H-cyclopenta[I]phenanthrene-2-one (i.e., phencyclone, 1, Scheme 1).

In view of the fact that 2-butyne-1,4-diol contains a relatively electron-rich carbon-carbon triple bond, this compound was not expected to function as an avid dienophile toward diene $\mathbf{1 .}$ Accordingly, the reaction of interest was performed at relatively high temperature, i.e., in refluxing xylene or in refluxing chlorobenzene (see the Experimental Section). Under these conditions, the desired [4 +2$]$ cycloaddition reaction to form 2 failed to take place. Instead, 
oxidative degradation of the cyclopentadienone ring in 1 occurred, thereby affording 3 in $40 \%$ yield. Compound 3 was characterized via analysis of its ${ }^{1} \mathrm{H}$ and ${ }^{13} \mathrm{C}$ nmr spectra (see the Experimental Section) and also via single crystal X-ray structural analysis (vide infra).

When 1 was refluxed in xylene in the absence of 2-butyne-1,4-diol, the deep black-green color associated with $\mathbf{1}$ gradually faded to a pale greenish-yellow solution. Workup of the reaction mixture afforded pure 3 in $72 \%$ yield. The IR, ${ }^{1} \mathrm{H} \mathrm{nmr}$, and ${ }^{13} \mathrm{C} \mathrm{nmr}$ spectra of the material thereby obtained were identical with the corresponding spectra obtained for $\mathbf{3}$ that had been obtained previously via attempted high temperature Diels-Alder cycloaddition of 2-butyne1,4-diol to 1 (vide supra).

It is well known that tetracyclones of the type $\mathbf{1}$ undergo both thermal ${ }^{2}$ and photochemical ${ }^{3}$ oxidative degradation in the presence of atmospheric $\mathrm{O}_{2}$ to afford compounds of the type 3 . Presumably, the thermal process proceeds via reaction of phencyclone with ground state (triplet) dioxygen $\left({ }^{3} \mathrm{O}_{2}\right)$. However, it should be recognized that compounds of the type 1 might function as photosensitizers and thus potentially could promote formation of singlet dioxygen $\left({ }^{1} \mathrm{O}_{2}\right)$, which then becomes the reactive oxidizing species. ${ }^{3}$<smiles>O=C1C(c2ccccc2)=c2c(c3ccccc3c3ccccc23)=C1c1ccccc1</smiles>

1

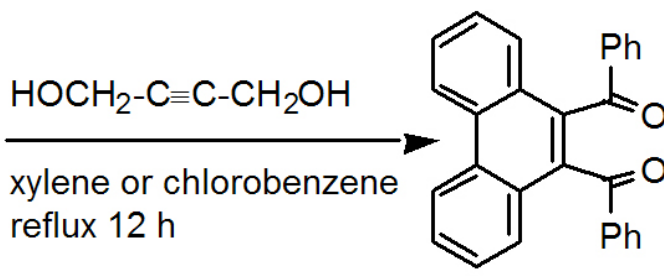

3<smiles>OCc1cc2c3ccccc3c3ccccc3c2c(-c2ccccc2)c1CO</smiles>

2 (not formed)

\section{Scheme 1}

In our hands, thermal autoxidation of phencyclone was performed in diffuse room light and in the presence of atmospheric $\mathrm{O}_{2}$. In order to investigate the potential role that photoactivation of ${ }^{3} \mathrm{O}_{2}$ to ${ }^{1} \mathrm{O}_{2}$ might play in the autoxidation of $\mathbf{1}$, a control experiment was performed in which a solution of $\mathbf{1}$ in xylene was refluxed with stirring overnight in the dark in the presence of atmospheric $\mathrm{O}_{2}$. Under these conditions, 3 was formed in $65 \%$ yield; this result suggests that autoxidation of $\mathbf{1}$ is promoted by ${ }^{3} \mathrm{O}_{2}$.

\section{Results and Discussion}

\section{Chemistry}

Reactions of ${ }^{1} \mathrm{O}_{2}$ with cyclic or cisoid acyclic 1,3-dienes frequently afford endoperoxides via Diels-Alder [4 + 2] cycloaddition. ${ }^{4}$ However, the corresponding concerted reaction that employs ${ }^{3} \mathrm{O}_{2}$ as dienophile is spin-forbidden. ${ }^{5}$ For this reason, the mechanism suggested in Scheme 2 invokes stepwise endoperoxide formation with initial formation of a diradical, 4, which 
subsequently suffers rapid spin-inversion and concomitant ring closure to afford $\mathbf{5}$. Thermal cycloreversion of $\mathbf{5}$, a spin-allowed process that proceeds via cheletropic extrusion of carbon monoxide, then leads to the formation of the observed reaction product, 3.

A potential competing process might involve thermally spin-allowed retro-Diels-Alder extrusion of dioxygen from intermediate $\mathbf{5}$. If this occurs, the starting material, i.e., $\mathbf{1}$, would be regenerated, along with ${ }^{1} \mathrm{O}_{2} \cdot{ }^{6}$

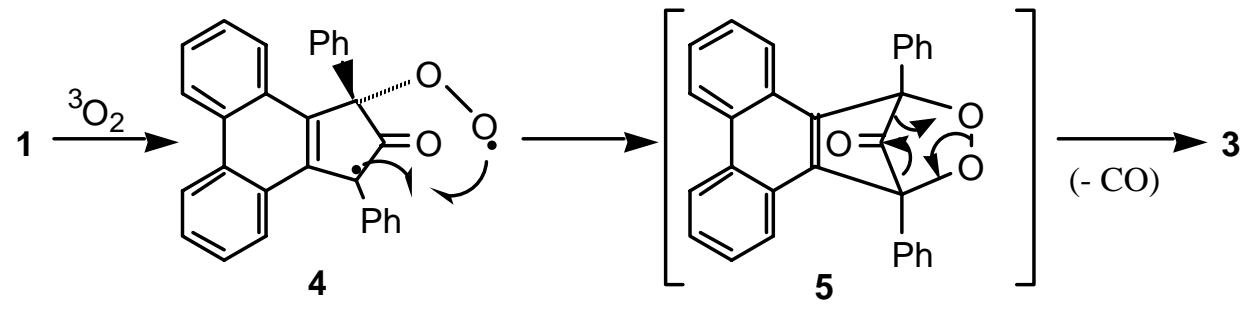

\section{Scheme 2}

In a separate experiment, $\mathrm{NaBH}_{4}$ promoted reduction of diketone 3 followed by aqueous acidic workup led to the formation of the corresponding 2,3-annulated furan (9). A mechanism that accounts for the formation of $\mathbf{9}$ in this reaction is shown in Scheme 3.<smiles>O=C(c1ccccc1)c1c(C(=O)c2ccccc2)c2ccccc2c2ccccc12</smiles>

3<smiles>[B]OC(c1ccccc1)c1c(C(=O)CCC)c2ccccc2c2ccccc12</smiles>

6<smiles>[B]OC1OC(c2ccccc2)c2c(C=C=C=C)cc3ccccc3c21</smiles>

7

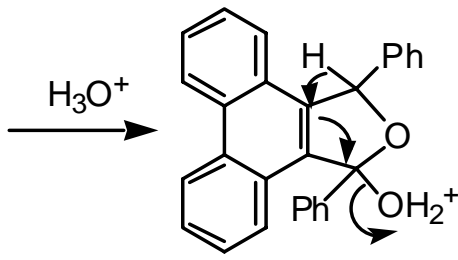

8<smiles>C[C@H](O)COc1ccccc1-c1c(-c2ccccc2)oc(-c2ccccc2)c1-c1ccccc1</smiles>

9

\section{Scheme 3}

\section{X-ray crystallography}

An X-ray structure drawing of $\mathbf{3}$ is shown in Figure 1. The phenanthrene moiety is planar; the two trans phenyl rings reside at dihedral angles of $79.1(2)^{\circ}$ and $80.8(2)^{\circ}$, respectively, relative to the plane of the phenanthrene rings. The two trans carbonyl groups are twisted slightly out of the phenyl planes $\left[\mathrm{O}(1)-\mathrm{C}(15)-\mathrm{C}(16)-\mathrm{C}(17)=165.5(3)^{\circ}\right.$ and $\left.\mathrm{O}(2)-\mathrm{C}(22)-\mathrm{C}(23)-\mathrm{C}(24)=-172.9(3)^{\circ}\right]$. 


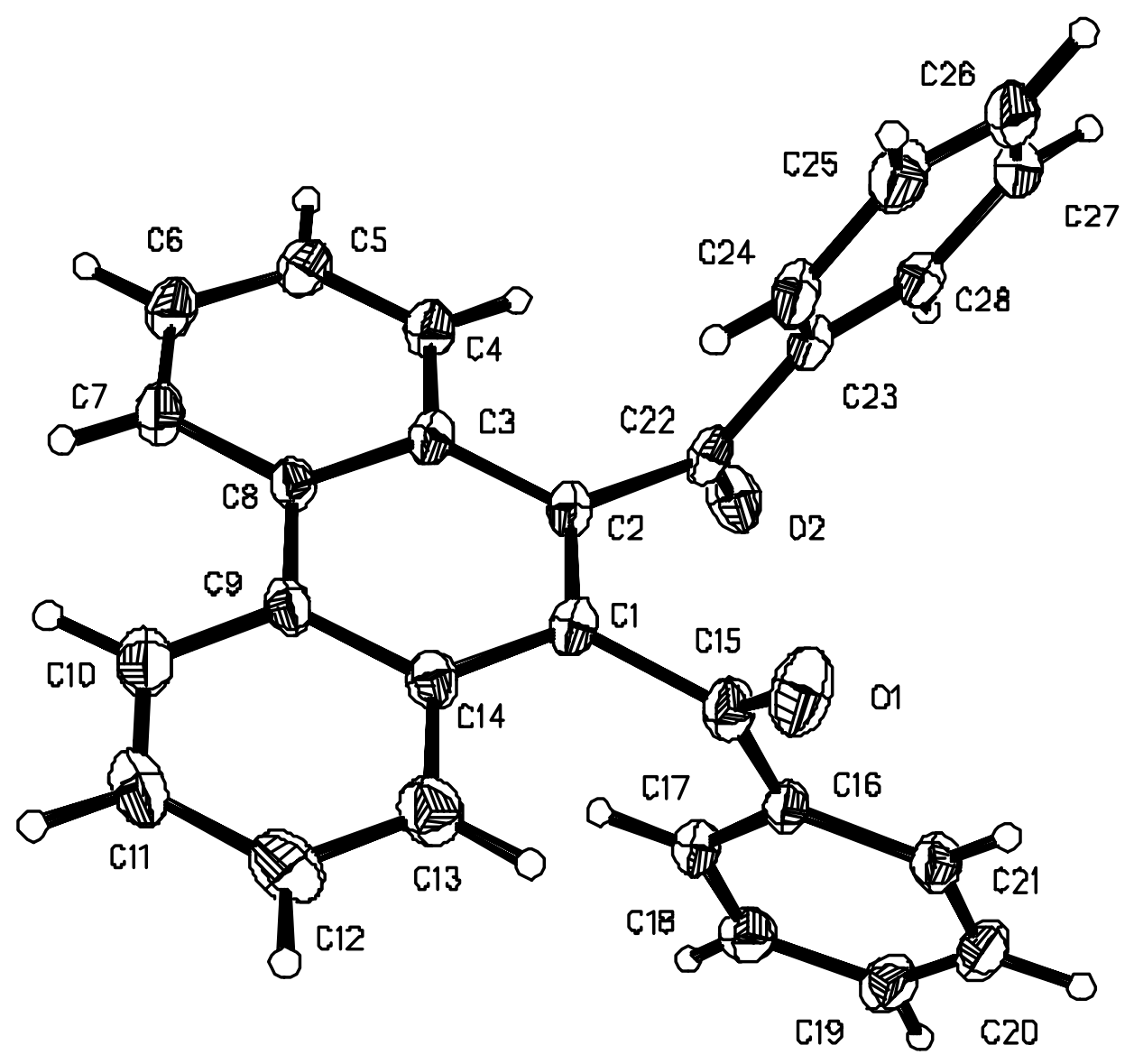

Figure 1. ORTEP-style thermal ellipsoid X-ray structure drawing of $\mathbf{3}$.

The corresponding crystal packing diagram (Figure 2) shows the orientations of the three planar groups in the structure. The shortest intermolecular distance is a weak interaction between a carbonyl oxygen and two phenyl hydrogen atoms on adjacent molecules. 


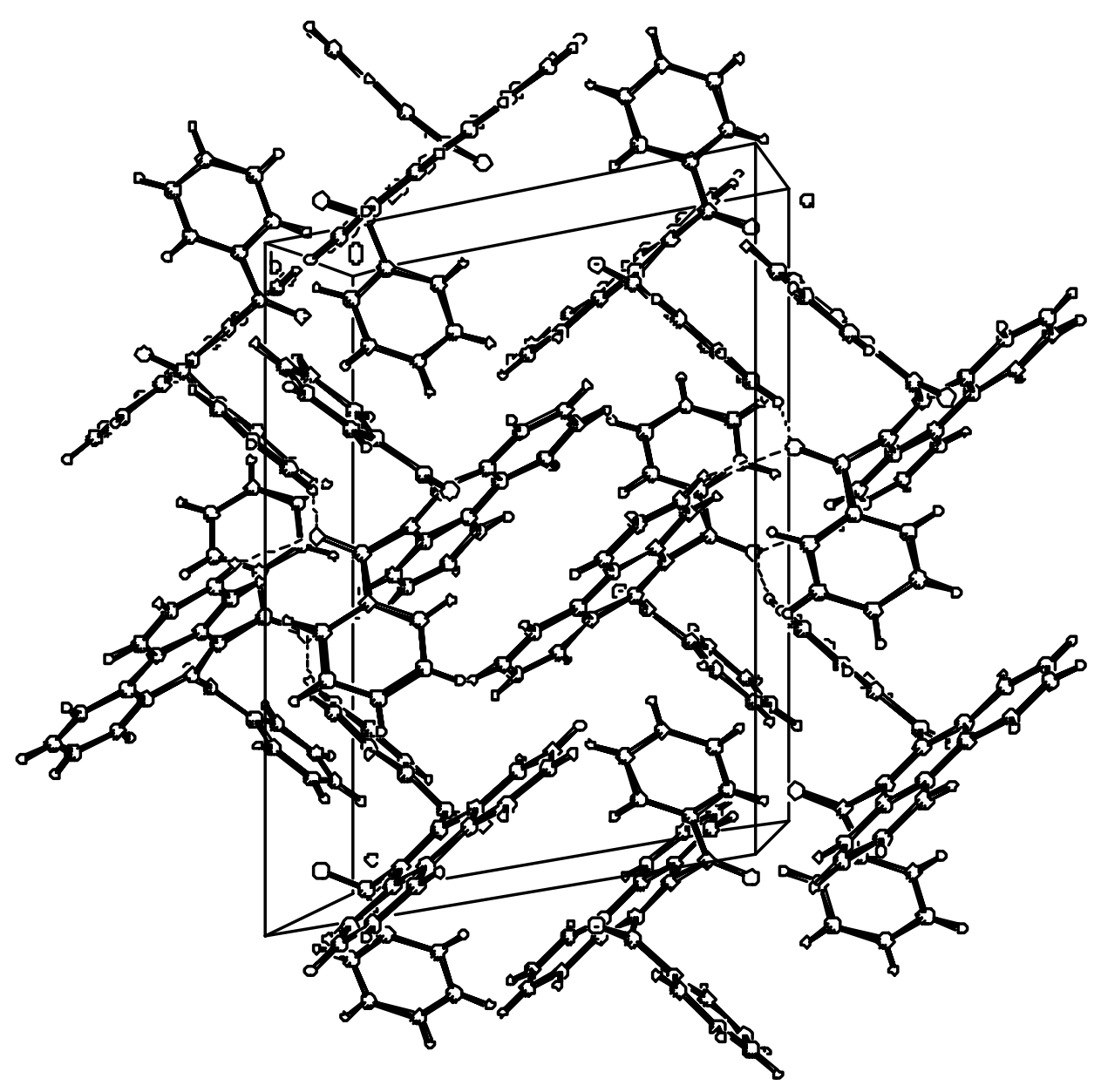

Figure 2. X-ray crystal packing diagram for 3.

\section{Conclusions}

9,10-Dibenzoylphanthrene (3) was prepared via thermal autoxidation of phencyclone (1) in the presence of atmospheric $\mathrm{O}_{2}$. The structure of $\mathbf{3}$ was elucidated via single crystal X-ray structural analysis. A mechanism is suggested in Scheme 2 to account for the formation of $\mathbf{3}$. It is believed that stepwise 1,4-addition of ${ }^{3} \mathrm{O}_{2}$ to the 1,3-diene system in the cyclopentadiene moiety of $\mathbf{1}$ occurs to form endoperoxide 5. Subequent cheletropic extrusion of carbon monoxide from 5 then leads to the formation of the observed autoxidation product, 3 . 


\section{Experimental Section}

General Procedures. Melting points were obtained on a Thomas Hoover Uni-Melt melting point capillary apparatus and are uncorrected, IR spectra were obtained by using a Midac Corp. Model 101025 infrared spectrophotometer. Proton nmr spectra (obtained at $200 \mathrm{MHz}$ ) and ${ }^{13} \mathrm{C}$ nmr spectra (obtained at $50.3 \mathrm{MHz}$ ) were run on a Varian Gemini 200 nuclear magnetic resonance spectrometer.

1,3-Diphenyl-2H-cyclopenta[I]phenanthrene-2-one (Phencyclone, 1). Phencyclone was prepared by using a modification of a published procedure. ${ }^{7}$ Thus, to a mixture of phenanthrene9,10-quinone (2.08 g, $10 \mathrm{mmol})$ and 1,3-diphenylacetone (2.31 g, $11 \mathrm{mmol})$ in EtOH (40 mL) was added dropwise with stirring at ambient temperature $20 \%$ ethanolic $\mathrm{KOH}$ ( $4 \mathrm{~mL}, 14 \mathrm{mmol}$ ). The initial yellow suspension gradually darkened to a black solution. This solution was cooled to $0-5{ }^{\circ} \mathrm{C}$ via application of an external ice-water bath, whereupon a precipitate formed gradually. This precipitate was collected via suction filtration, and the residue was washed with cold EtOH (15 mL). Pure 1 (1.85 g, 48\%) was thereby obtained as a black microcrystalline solid: mp 243$245^{\circ} \mathrm{C}$ (lit. mp $226{ }^{\circ} \mathrm{C},{ }^{2} \mathrm{mp}$ 243-246 ${ }^{\circ} \mathrm{C}^{7}$ ); IR (KBr) 3062 (w), 1697 (s), 1443 (m), 1100 (m), 750 (s), 729 (s), $695 \mathrm{~cm}^{-1}(\mathrm{~s})$; ${ }^{1} \mathrm{H}$ NMR $\left(\mathrm{CDCl}_{3}\right) \delta$ 6.88-6.98 (m, $\left.2 \mathrm{H}\right), 7.21-7.28$ (m, $\left.2 \mathrm{H}\right)$, 7.347.45 (m, $10 \mathrm{H}$ ), 7.53 (d, $J=8.4 \mathrm{~Hz}, 2 \mathrm{H}$ ), 7.79 (d, $J=8.4 \mathrm{~Hz}, 2 \mathrm{H}) ;{ }^{13} \mathrm{C} \mathrm{NMR}\left(\mathrm{CDCl}_{3}\right) \delta 123.1$ (s), 124.4 (d), 128.2 (d), 128.3 (d), 128.5 (s), 128.6 (d), 129.0 (d), 130.0 (d), 131.4 (d), 132.3 (s),133.5 (s), 148.2 (s), 199.7 (s). This material was used as obtained in the next step, without additional purification.

9,10-Dibenzoylphenanthrene (3). Method A. A solution of 1 (200 mg, $0.52 \mathrm{mmol}$ ) in either xylene $(20 \mathrm{~mL})$ or chlorobenzene $(20 \mathrm{~mL})$ was refluxed with stirring during $4 \mathrm{~h}$. No special precautions were taken to exclude atmospheric oxygen. The reaction mixture was allowed to cool gradually to ambient temperature and then was concentrated in vacuo. The residue was purified via column chromatography on silica gel by eluting with 2\% EtOAc-hexane. Pure 3 (140 mg, 72\%) was thereby obtained as a colorless microcrystalline solid: mp $206-207^{\circ} \mathrm{C}$ (lit. ${ }^{8}$ mp $206{ }^{\circ} \mathrm{C}$ ); IR (KBr) 3057 (s), 1663 (s), 1447 (s), 1231 (s), 760 (s), 708 cm-1 (s); ${ }^{1} \mathrm{H}$ NMR $\left(\mathrm{CDCl}_{3}\right) \delta$ 7.30-7.42 (m, $\left.4 \mathrm{H}\right), 7.48-7.60(\mathrm{~m}, 4 \mathrm{H}), 7.66-7.90(\mathrm{~m}, 8 \mathrm{H}), 8.81(\mathrm{~d}, J=8.7 \mathrm{~Hz}, 2 \mathrm{H})$; ${ }^{13} \mathrm{C}$ NMR $\left(\mathrm{CDCl}_{3}\right) \delta 123.5$ (d), 127.75 (d), 127.79 (d), 127.9 (d), 128.5 (d), 128.9 (s), 130.6 (d), 131.0 (s), 134.3 (d), 135.8 (s), 138.1 (s), 198.7 (s).

9,10-Dibenzoylphenanthrene (3). Method B. A solution of 1 (135 mg, $0.35 \mathrm{mmol}$ ) in xylene $(10 \mathrm{~mL})$ was refluxed overnight in the dark during $12 \mathrm{~h}$. No precautions were taken to exclude atmospheric $\mathrm{O}_{2}$. After the reflux period had concluded, the reaction mixture was allowed to cool gradually to ambient temperature and then was concentrated in vacuo. The residue was purified via column chromatography on silica gel by eluting with $2 \%$ EtOAc-hexane. Pure 3 (88 mg, $65 \%$ ) was thereby obtained as a colorless microcrystalline solid: mp $206-207{ }^{\circ} \mathrm{C}$. The $\mathrm{IR},{ }^{1} \mathrm{H}$ 
$\mathrm{nmr}$, and ${ }^{13} \mathrm{C}$ nmr spectral data for this material were essentially identical to the corresponding spectra obtained for $\mathbf{3}$ that had been prepared previously by using Method A (vide supra).

Sodium Borohydride Promoted Reduction of 3. To a solution of 3 (150 mg, $0.39 \mathrm{mmol}$ ) in $\mathrm{MeOH}(15 \mathrm{~mL})$ under argon at ambient temperature was added portionwise with stirring $\mathrm{NaBH}_{4}$ (38 mg, $1.0 \mathrm{mmol}$ ). After all of the reducing agent had been added, the reaction mixture was stirred at ambient temperature during $8 \mathrm{~h}$ and then was quenched via careful dropwise addition of $10 \%$ aqueous $\mathrm{HCl}\left(15 \mathrm{~mL}\right.$, excess). The resulting mixture was extracted with $\mathrm{CH}_{2} \mathrm{Cl}_{2}(2 \times 30$ $\mathrm{mL})$. The combined organic extracts were washed sequentially with water (20 mL) and brine (15 $\mathrm{mL})$, dried $\left(\mathrm{Na}_{2} \mathrm{SO}_{4}\right)$ and filtered, and the filtrate was concentrated in vacuo. The residue was purified via column chromatography on silica gel by eluting with hexane. Pure 9 (122 mg, 85\%) was thereby obtained as a spongy white solid: mp 178-179 ${ }^{\circ} \mathrm{C}$ (lit. ${ }^{2} \mathrm{mp} 185^{\circ} \mathrm{C}$ ); IR (KBr) 3054 (s), 1484 (m), 1432 (m), 950 (m) 745 (s), $692 \mathrm{~cm}^{-1}$ (s); ${ }^{1} \mathrm{H}$ NMR $\left(\mathrm{CDCl}_{3}\right) \delta$ 7.22-7.31 (m, 2H), 7.38-7.57 (m, 8H), 7.82 (dd, $\left.J_{1}=7.7 \mathrm{~Hz}, J_{2}=0.7 \mathrm{~Hz}, 4 \mathrm{H}\right), 8.17$ (dd, $J_{1}=7.9 \mathrm{~Hz}, J_{2}=1.3 \mathrm{~Hz}$, $2 \mathrm{H}), 8.35$ (dd, $\left.J_{1}=8.1 \mathrm{~Hz}, J_{2}=0.8 \mathrm{~Hz}, 2 \mathrm{H}\right) ;{ }^{13} \mathrm{C} \mathrm{NMR}\left(\mathrm{CDCl}_{3}\right) \delta 117.3$ (s), 123.8 (d), 124.1 (d), 126.9 (d), 127.0 (s), 127.1 (d), 128.7 (d), 128.8 (d), 129.3 (d), 130.6 (s), 132.6 (s), 147.1 (s).

X-ray Structure Determination of 3. X-ray data were collected on a Bruker SMARTTM 1000 CCD-based diffractometer. The frames were integrated with the SAINT software package ${ }^{9}$ by using a narrow frame algorithm, and the structre was solved and refined using the SHELXTL program package. ${ }^{10}$ The structure was checked with PLATON. ${ }^{11}$ Crystal data, collection parameters, and refinement criteria for compound $\mathbf{3}$ are presented in Table 1.

Table 1. Crystal data and structure refinement for compound 3

Compound

Formula

Size $(\mathrm{mm})$

Space Group

a $(\AA)$

$\mathrm{b}(\AA)$

c $(\AA)$

$\alpha\left(^{\circ}\right)$

$\beta\left(^{\circ}\right)$

$\gamma\left({ }^{\circ}\right)$

$\mathrm{V}\left(\AA^{3}\right)$

Z-value
3

$\mathrm{C}_{28} \mathrm{H}_{18} \mathrm{O}_{2}$
$0.18_{-} 0.16_{-} 0.16$
$\mathrm{P}_{2} 1_{\mathrm{C}}$
$12.116(2)$
$9.6850(2)$
$16.839(3)$
90
$100.331(3)$
90
$1943.9(5)$
4

$\begin{array}{ll}\mathrm{D}_{\text {calc }}\left(\mathrm{g}-\mathrm{cm}^{-3}\right) & 1.320 \\ \mu\left(\mathrm{mm}^{-1}\right) & 0.082 \\ \mathrm{~T}(\mathrm{~K}) & 213(2) \\ 2 \theta \text { range }\left(^{\circ}\right) & 1.71 \text { to } 20.81 \\ \text { Total reflections } & 6639 \\ \text { Independent } & 2037 \\ \text { reflections } & \\ \text { Rint } & 0.0609 \\ \text { Data/restraints/ } & 2037 / 0 / 272 \\ \text { parameters } & \\ \text { R, R(all) } & 0.0461,0.0808 \\ \text { GOF } & 1.007 \\ \text { Extinction correction } & 0.0016(7)\end{array}$




\section{Acknowledgments}

We thank the Robert A. Welch Foundation [Grants B-0963 (A. P. M) and P-0074 (W. H. W.)] for financial support of this study. In addition, we thank the Texas Advanced Technology Program [Grant 003659-0206-1999 (A. P. M.)] and the U. S. Department of Energy [Grant DEFG07-98ER14936 (A. P. M.)] for additional financial support of the work reported herein.

\section{References and Notes}

1. For leading references, see: Marchand, A. P.; Kumar, K. A.; McKim, A. S.; Alihodzic, S.; Chong, H.-S.; Krishnudu, K.; Takhi, M.; Mlinaric-Majerski, K.; Kragol, G.; Sumanovac, T. Kem. Ind. 2001, 50, 129.

2. Dilthey, W.; Henkels, S.; Leonhard, H. J. Prakt. Chem. 1938, 151, 97.

3. Foote, C. S.; Wexler, S. J. Am. Chem. Soc. 1964, 86, 3879.

4. Foote, C. S.; Clennan, E. L. in: Active Oxygen in Chemistry, Foote, C. S.; Valentine, J. S.; Greenberg, A.; Liebman, J. F., Eds., Blackie Academic \& Professional: New York, 1995, Chapter 4, pp 105-140.

5. Seip, M.; Brauer, H. D. J. Am. Chem. Soc. 1992, 114, 4486.

6. Acene endoperoxides frequently undergo thermal decomposition to afford ${ }^{1} \mathrm{O}_{2}$; see: Saito, I.; Matsuura, T. in: Singlet Oxygen, Wasserman, H. H.; Murray, R. W., Eds. Academic Press: New York, 1979, pp 524-526.

7. (a) Dilthey, W.; ter Horst, I.; Schommer, W. J. Prakt. Chem. 1935, 143, 189. (b) Pascal Jr., R. A.; Engen, D. V.; Khar, B.;McMillan, W. D. J. Org. Chem. 1988, 53, 1687.

8. Baidossi, W.; Schumann, H.; Blum, J. Tetrahedron 1996, 52, 8349.

9. SAINT, Version 6.02, Bruker Analytical X-ray Systems, Inc. Copyright 1997-1999.

10. SHELXTL, Version 5.1, Bruker Analytical X-ray Systems, Inc. Copyright 1998.

11. (a) Spek, A.L. Acta Cryst. 1990, A46, C34. (b) Spek, A. L. PLATON - A Multipurpose Crystallographic Tool, University of Utrecht, Utrecht, The Netherlands (2001). 